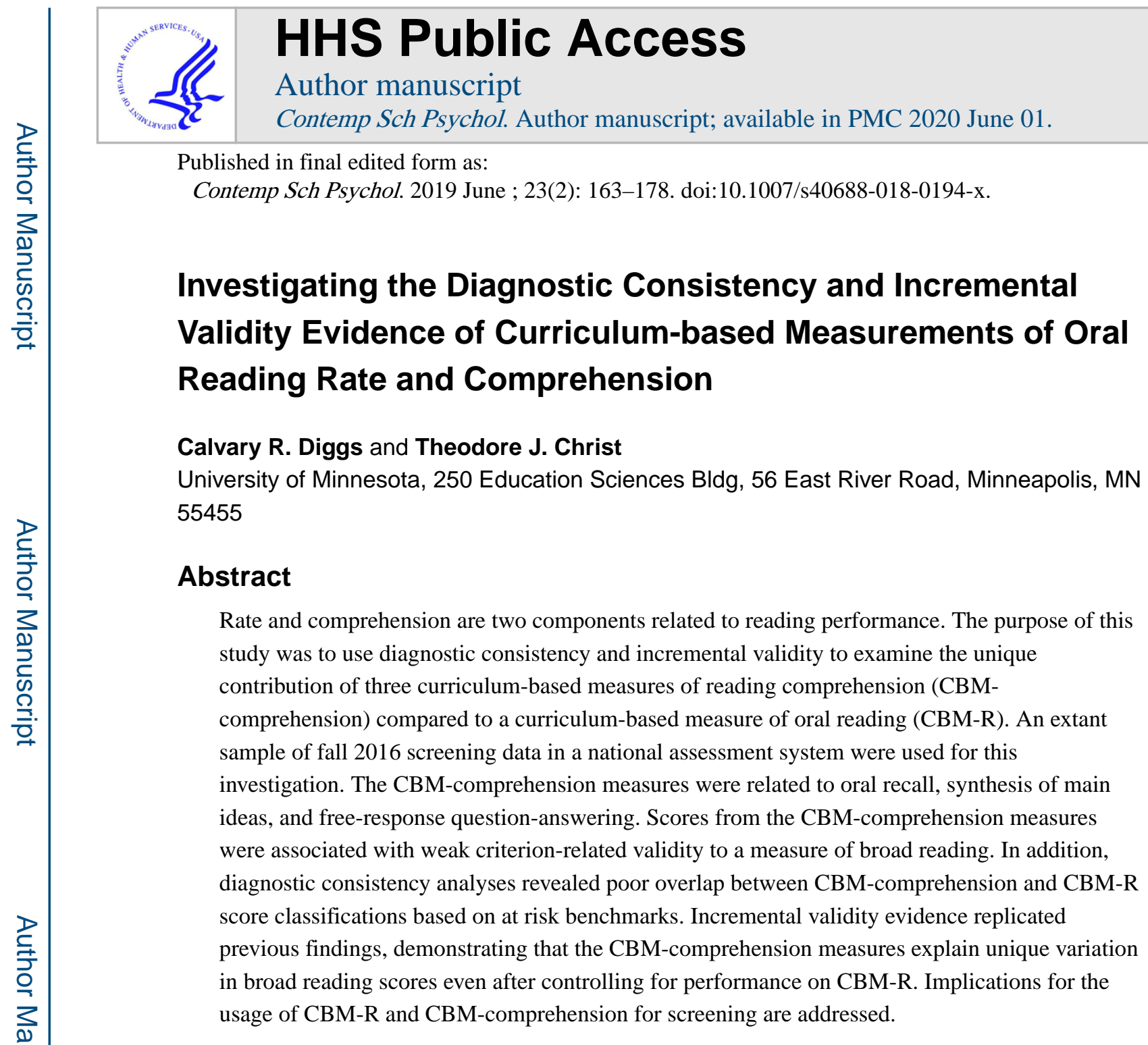

\title{
Keywords
}

Reading; Comprehension; CBM; Screening; Assessment; Assessment-to-Intervention

\begin{abstract}
Universal screening in reading has the capacity to inform data-based decisions regarding the supports needed for students who may not achieve proficiency on year-end competencies (Ball \& Christ, 2012; Christ \& Keller-Margulis, 2014; Deno, 1985; Fuchs \& Fuchs, 2006). Year-end competencies may vary; however, they broadly address areas of reading such as phonological awareness (e.g., distinguishing long and short sounds), phonics (e.g., decode common prefixes and suffixes), fluency (e.g., read poetry with expression), vocabulary (e.g.,
\end{abstract}

\footnotetext{
diggs042@umn.edu, 704-605-5136, 0000-0002-6675-6340, tchrist@umn.edu, 612-624-7068, 0000-0002-5397-0364.

Calvary Diggs has no conflict of interest.

Compliance with Ethical Standards

Ethical Approval

All procedures performed in this study involving human participants were in accordance with the ethical standards of the institutional research committee and with the 1964 Helsinki declaration and its later amendments or comparable ethical standards.

Informed consent

Informed consent was obtained from all individual participants included in the study.
} 
learn and understand domain-specific terms), and comprehension (e.g., summarize the main ideas and supporting details in a text; National Governors Association Center for Best Practices, Council of Chief State School Officers, 2010). In schools, screening for reading difficulties is becoming a part of common practice, and in some states it's mandated (VanDerHeyden \& Burns, 2017). Curriculum-based measures of oral reading (CBM-R) is a common screening task used in schools to detect reading difficulties and monitor reading development in phonics knowledge and reading rate. Students are given a passage of connected text and asked to read aloud for one minute. The words read correct per minute (WRCM) score obtained from administering CBM-R is a direct measure of rate, which is reading with speed and minimal errors. Rate is similar to fluency, but it does not measure intonation or prosody. Instead, rate is a more precise term that is easier to reliably quantify (Kuhn, Schwanenflugel, Meisinger, Levy, \& Rasinski, 2010).

By using CBM-R as a screener of broad reading difficulties, schools can detect and serve students who score below a set criterion (e.g., national norms, benchmarks) that is related to typical performance expectations and the likelihood that students will reach proficiency on national and other meaningful measures of broad reading achievement (Daly \& Martens, 2007; Shapiro, 2011). Students with needs on CBM-R (thereby suspected needs on other measures of broad reading) can be supported by improving their oral reading rate or phonics knowledge through direct instruction and repeated practice (Morgan, Sideridis, \& Hua, 2012; Strickland, Boon, \& Spencer, 2013; Yang, 2007). However, American students currently demonstrate low performance on national measures of broad reading achievement (National Center on Education Statistics, 2015), which is associated with later school dropout when performance is below a minimum third-grade standard (Alexander, Entwisle, \& Kabbini, 2001). Such findings suggest that students at risk of failing to meet basic reading competencies should be identified and supported, not only in oral reading rate but also other areas of broad reading ability, such as comprehension.

Despite the emphasis on decoding at a fast and accurate rate, comprehension is paramount to reading development (Gough \& Tunmer, 1986; The National Reading Panel [NRP] (2000), p.4-11). Thus, technically adequate, theoretically supported, and instructionally relevant assessments are needed in not only reading rate but also comprehension in order to better inform the assessment to intervention process (Graesser \& Hu, 2012). Assessment to Intervention in Reading: Why CBM-R Might Not be Enough

Findings suggest rate predicts and explains significant variance on assessments of broad reading ability (Fuchs, Fuchs, \& Compton, 2004; Fuchs, Fuchs, \& Maxwell, 1988; Hintze \& Silberglitt, 2005; Wayman, Wallace, Wiley, Tichá, \& Espin, 2007). In addition, a metaanalysis of 289 studies of correlations between CBM-R and measures of reading achievement reported an overall correlation of .68 ( $\mathrm{SD}=.06$; Reschly, et al., 2009). Furthermore, both studies and reviews suggest there is adequate reliability evidence (ranging from .82 to .99) to support the instructional utility of CBM-R (Ardoin \& Christ, 2008; Graney, Martínez, Missall, \& Aricak, 2010; Kilgus, Methe, Maggin, \& Tomasula, 2014; Wayman et al., 2007). Altogether, these findings indicate that CBM-R has a robust, stable relationship with measures of reading achievement; however, similar findings in reading comprehension are not as apparent. 
In comparison to CBM-R, assessment of reading comprehension is broader, including various measurement foci and delivery formats (Ardoin et al., 2013; Carlson, Seipel, \& McMaster, 2014; Davis \& Guthrie, 2015; Fuchs, 1988). For example, there are common measures of reading comprehension that schools may use, but their methods may be different. For example, DIBELS-Retell Fluency is used following CBM-R to measure comprehension. It is used to monitor the number of words students produce as they provide details about the passage they just read during a 1-minute retell of the CBM-R passage (Good \& Kaminski, 2002). In contrast, CBM-Maze is a passage with words systematically deleted, and students are required to select a word from several choices that is appropriate in context (Ford, Missal, Hosp, \& Kuhle, 2016). Scores on similar measures of reading comprehension seldom demonstrate higher correlations and predictive power with broad reading that are superior to CBM-R (Christ, White, Ardoin, \& Eckert, 2013; Fuchs et al., 1988). Thus, there may be some utility in investigating other measures that use different components of comprehension and inferences that remain authentic to instruction (Perfetti \& Adlof, 2012; McNamara \& Magliano, 2009).

Given the findings for CBM-R and comprehension measures, it is reasonable to question the utility of reading comprehension measures beyond CBM-R. Still, reading comprehension assessments useful for practices relevant to screening and intervention selection are needed for the following reason: a measure of reading rate does not provide a holistic description of a student's reading (Gough \& Tunmer, 1986; Kendeou, Papadopoulos, \& Spanoudiset, al., 2012; Kranzler, Miller, \& Jordan, 1999; Stanovich, 1986; Tunmer \& Chapman, 2012).

Multiple sources of information are likely needed to provide comprehensive and meaningful detection and intervention practices for students at risk of problems in reading (Christ \& Aranas, 2014).

\section{Purpose of the Present Study}

Schools should be able to detect and intervene for students with difficulties in reading rate and comprehension. The purpose of this study was to contribute to improving school-based assessment to intervention systems by investigating how measures of reading comprehension and oral reading rate function as related but distinct measures of broad reading. This study investigated the typical use of (a) CBM-R without direct measures of reading comprehension and (b) CBM-R with three novel CBM-comprehension tasks authentic to school-based comprehension demands that included oral recall of literal and inferential information (recall), identification of key points (retell synthesis), and various inferential connections (questions).

It was expected that (a) the criterion validity coefficients for broad reading and reading rate and comprehension would suggest a relationship, (b) the diagnostic consistency between CBM-R and CBM-comprehension scores would be poor, (c) the CBM-comprehension measures would demonstrate incremental validity evidence above and beyond CBM-R when broad reading is the criterion, and (d) results would provide preliminary evidence on the utility of the CBM-comprehension measures as supplements to CBM-R in universal screening efforts. 


\section{Method}

\section{Participants}

Population-This study consisted of 8,357 students from 165 schools across 24 states. Students were in 2 nd to 5 th grade. Students were de-identified, with each student having a unique participant and school identification number. Schools reported demographic data for $44 \%$ of the students in this sample as $48 \%$ White, 10\% Black or African American, 29\% Hispanic, $1 \%$ American Indian or Alaska natives, 3\% Asian, $0.2 \%$ native Hawaiian or other pacific islander, $4 \%$ Multiracial, and 6\% were identified as Other. In addition, the special education status was identified for $15 \%$ of the sample, where $82 \%$ were identified as not eligible for special education, $1 \%$ had a specific learning disability, $3 \%$ had speech or language impairments, $1 \%$ had emotional disturbance, $2 \%$ had multiple disabilities, $2 \%$ had other health impairment, $1 \%$ had autism, $2 \%$ had other disabilities, and $6 \%$ had disabilities that were not specified. Gender was reported for $94 \%$ of the sample, with $48 \%$ identified as female and $52 \%$ identified as male. The four states with the greatest representation were Louisiana (27\%), Minnesota (19\%), New York (16\%), and Illinois (14\%). Those four states represented $75 \%$ of the sample.

Sampling-Data were collected from an online assessment system (FastBridge Learning [FBL]; TJCC, 2015) used by schools to access and store screening and progress monitoring data. Only data relevant to the present study were retrieved from the system. Schools within the system are self-selected, as they pay to use the system.

\section{Measures}

aReading-The broadest measure of reading skills used in this study was aReading, which is a 30-item computer adaptive test that samples skills across a range of reading abilities. Although it does not measure reading rate, aReading is a direct measure of broad reading (i.e., phonological, orthographic, and sematic skills, which include vocabulary and comprehension). aReading utilizes scaled scores with a mean score of 500 with a standard deviation of 50. The measure has a test-retest of .79, Cronbach's alpha of .95, and construct and predictive validity above the .70 standard (NCRTI, 2015). The assessment takes approximately 30 minutes.

Curriculum-based measurement of oral reading-CBM-R is a direct measure of the accuracy and rate of passage reading, which are primarily phonological and orthographic skills (Fuchs et al., 2001). Students were asked to read aloud three novel, grade level passages for one minute each, while an examiner recorded errors associated with non-fluent reading (e.g., hesitations, mispronunciations). The words a student read correct in one minute (WRCM) were paired with a measure of accuracy (words read correct divided by total words read) to provide a picture of student rate and accuracy. CBM-R scores for this study were gathered by selecting the median WRCM score over three equivalent passages. The accuracy associated with the median WRCM score was also selected for the analyses.

Curriculum-based measurements of comprehension-The CBM-comprehension measures were developed for use as direct measures of reading comprehension. Together, 
the measures used in this study describe oral production comprehension following the reading of CBM-R. These measures were selected due to their novelty from the maze task in that they are indices of oral production comprehension, constructed response, administered immediately following CBM-R, and take about five minutes to administer. No reliability and validity evidence regarding these measures was available at the time this study.

Comprehension recall: Comprehension recall (CompD) was administered following the third CBM-R timed reading. Students continued reading until they reached the end of the passage. Once completed, the passage was removed, and students were given two minutes to retell all that they remembered. If pauses occurred that lasted for five seconds, the assessor asked, "Anything else?" The scale for CompD ranged from 0 to 20 discrete details. Assessors matched students' oral retell to details as students spoke.

Comprehension synthesis: The information used to score comprehension synthesis (CompS) was gathered from the timed two-minute retell for CompD. To calculate the CompS score, the system automatically scored six predetermined key details based on student responses in CompD. Those results were tallied to calculate scores for CompS, ranging from 0 to 6 .

Comprehension questions: The comprehension questions (CompQ) measure was administered following the third CBM-R timed reading and CompD and CompS. Students were asked ten predetermined open-ended questions about the final CBM-R probe. Students either provided the correct verbal response or an incorrect one. Scores ranged from 0 to 10.

\section{Procedures}

$\mathrm{R}$ was used for the descriptive, validity, and diagnostic consistency analyses conducted in the present study. Of note, Receiver Operator Curves (ROC; Swets, Dawes, \& Monahan, 2000) were used to evaluate the diagnostic consistency of decisions, which defined the extent to which reading comprehension and rate classifications (as determined by empirical benchmarks) converged. Information is reported in terms of

- True Negative (TN), which represents the proportion of students receiving the diagnostic classifications of proficient on both WRCM and CBMcomprehension;

- False Negative $(\mathbf{F N})$, which represents the proportion of students receiving the diagnostic classifications of proficient on WRCM but at risk on CBMcomprehension;

- True Positive (TP), which represents the proportion of students receiving the diagnostic classifications of at risk readers on both WRCM and CBMcomprehension;

- False Positive (FP), which represents the proportion of students receiving the diagnostic classifications of at risk readers on WRCM but proficient on CBMcomprehension; 
- Hit Rate, which is the proportion of consistent classifications (i.e., agreement) between WRCM and the CBM-comprehension measure;

- Sensitivity, which is the true positive or consistent classification rate of risk on both assessments (i.e., poor readers in both comprehension and WRCM);

- Specificity, which is the true negative or consistent classification rate of low risk on both assessments (i.e., good readers in both comprehension and WRCM);

- Positive Predictive Value (PPV), which is the likelihood that someone considered at risk in WRCM is also considered at risk in CBM-comprehension;

- Negative Predictive Value (NPV), which is the likelihood that someone considered at low risk in WRCM is also considered at low risk in CBMcomprehension; and

- Area Under the Curve (AUC), which is the proportion of students correctly identified on both measures as at risk compared to the proportion of students classified as low risk on CBM-comprehension but high risk on WRCM (i.e., sensitivity compared to 1 minus specificity).

\section{Results}

A review of the dataset identified 51 outliers $(z>4.0)$, no duplicates, and 72 incomplete entries. In total, 123 cases (1.5\%) were removed prior to analysis. Further review of the data indicated they met the assumptions for inferential analyses.

Table 1 provides a review of descriptive information for each measure by grade. The average scores in each grade for each measure were at or near the benchmark for low risk (Table 1).

Although there was some variation across grades and measures, typically, the highest performance above benchmark was in Grade 2 and lowest performance in Grade 5. Together, these descriptive data suggest similarities in average student performance on various measures of reading. This provides support for the analyses to follow. Specifically, analyses first examined the criterion-related validity evidence of scores on CBM-R and CBMcomprehension measures.

\section{Criterion Validity Evidence}

Table 2 presents means, standard deviations, and correlations between each measure for each grade level. The strength of the Pearson product-moment relationships were interpreted as less than .50 is weak, .50 to .70 is moderate, and more than .70 is a strong criterion validity evidence. Criterion validity coefficients using broad reading (aReading) were small to moderate for the comprehension measures ( $M d n=.41$; range, .15 to .5$)$ and moderate for CBM-R accuracy ( $M d n=.55$; range, .47 to .67 ; Cohen, 1985). Coefficients for both comprehension and CBM-R accuracy were all below the conventional standard of .70 for the criterion validity of screening measures (National Center for Response to Intervention [NCRTI], 2015). The strength of the relationships between broad reading and WRCM was moderate to strong ( $M d n=.74$; range, .65 to .77$)$. The strength of the correlations between CompQ with CompD and CompS were moderate ( $M d n=.57$; range, .53 to .67$)$. Of note, the 
relationship between CompD and CompS was strong ( $M d n=.84$; range, .80 to .85$)$, but those scores were derived from the same task.

\section{Diagnostic Consistency Evidence}

Receiver Operator Curves (ROC; Swets, Dawes, \& Monahan, 2000) were used to evaluate the diagnostic consistency of decisions, which defined the extent to which reading comprehension and rate classifications (as determined by empirical benchmarks) converged. Table 3 presents findings from the diagnostic consistency analysis, which defined CBMcomprehension scores as the criterions and WRCM as the predictor. The analysis provides an indication of how well WRCM indicate comprehension performance according to various indices.

Overall, AUC estimates were all above that of chance, or .50 (Swets, et al., 2000). This is indicated by the $95 \%$ confidence intervals that do not span the value of .50 , which is the value that indicates a $50 \%$ chance of a correct classification (Table 3). Although distinct from chance, AUCs were consistently below .70, which is a standard for acceptable classification accuracy (Compton et al., 2010). The largest of AUC were observed in second grade for CompQ (.65), CompD (.67), and CompS (.66). The lowest AUCs were in fifth grade for CompQ (.58), CompD (.56), and CompS (.55).

Analysis was conducted with FBL benchmarks to evaluate classification agreements between each CBM-comprehension assessment (criterion) and CBM-R (predictor). The median of the hit rates (i.e., agreements) for positive classifications across measures and grades was 63\% (range, 55-69\%). The highest hit rate for agreement was observed for second grade for CompQ (.66), CompD (.69), and CompS (.67). The lowest hit rates for agreement were observed in fifth grade for CompQ (.58), CompD (.58), and CompS (.55).

The sensitivity and specificity estimates were consistent across all measures within each grade with medians of .63 (range, .55-.70) and .59 (range, .43-.76), respectively. Although similar, the lowest sensitivities and highest specificities were all observed in second grade. Based on the estimates of false negatives ( $M d n=.19$; range, .12-.24) and false positives ( $M d n=.22$; range, .14-.28), 12 to $28 \%$ of students were classified incorrectly when CBM-R was used to indicate comprehension proficiency.

The proportion of students under each classification profile-or base rate (i.e., TN, TP, FP, FN)-is represented in both Table 3 and Figure 1. Figure 1 provides a visual example of the data. Both show that, overall, students' similar profiles in rate and comprehension were more common than discordant profiles for each measure and within each grade for all 12 instances. In addition, students with high reading rate and low comprehension (FN) tended to have the lowest base rates in fifth grade for each measure.

\section{Incremental Validity Evidence}

Multiple regression was used to explore if the additional variation in broad reading scores was predicted by CBM-comprehension scores. Table 4 displays incremental and predictive validity evidence of the predictor variables to that of broad reading. Models were built in concordance with stepwise procedures, beginning with accuracy and ending with the CBM- 
comprehension measures. This was done to align with reading theory wherein students acquire an understanding of alphabetic principles (Model 1), then develop reading rate (Model 2), which reduces the effort required for decoding and allows more resources to be used on the higher order process of reading comprehension (Models 3 to 5; Ehri, 2005; Gough \& Tunmer, 1986). Furthermore, the individual comprehension measures were entered based on the time and effort required to administer them, with CompQ (Model 3) as the easiest and most efficient, CompD as more demanding (Model 4), and CompS emerged from the items scored as part of CompD (Model 5). Interactions (Model 6) were examined, but only the significant interactions are presented in Table 4. Finally, the Benjamani-Hochberg method was used to control for compounded type II familywise error (Schochet, 2008). This method was applied to the final model at each grade to test significance.

In all grades, as WRCM increased on average, so did broad reading. In addition, the estimated slope decreased compared to 2 nd grade $\left(\beta 2\left[2^{\text {nd }}, 3^{\text {rd }}, 4^{\text {th }}, 5^{\text {th }}\right]=.35, .24, .26, .26\right)$. Controlling for all other variables, the largest parameter estimates were observed for reading accuracy, with the slope estimates that ranged from approximately 31 to 92 points on the criterion measure of broad reading.

In all grades, at least one of the measures of comprehension explained additional variance above and beyond that of CBM-R accuracy and WRCM. CompQ was a statistically significant $(a=.05)$ predictor of broad reading above and beyond that of WRCM and accuracy at grades 2,4 , and 5 . When added to that model, CompD was a significant predictor in grades 3, 4, and 5. When added to the next model, CompS was a significant predictor in grades 2,4 , and 5 . Holding all predictors in the model constant, interaction effects were significant at grades $2(\mathrm{CompD} \times \mathrm{WRCM}), 3(\mathrm{WRCM} \times \mathrm{CompQ})$, and 4 $(\mathrm{WRCM} \times \mathrm{CompS})$.

The incremental validity evidence of the comprehension measures can be observed from the first model compared to the final model for each grade in Table 4. The total R-square change in variance explained by the reading comprehension scores (i.e., the final model) ranged from 2.01 to $5.90(M d n=3.33)$. Comprehension measures explained more variance in grades 4 and 5 .

The beta coefficients for the comprehension measures in the final model tended to be positive ( $M d n=0.61$; range, -2.22 to 1.68 ), which indicated that after accounting for accuracy and rate, higher levels of performance on comprehension measures corresponded with higher levels of broad reading performance.

Controlling only for wrcm-Table 5 represents the incremental validity evidence associated with adding a single CBM-comprehension score to explain variation in broad reading as the criterion, controlling for WRCM. For each grade and controlling for WRCM, each measure of reading comprehension predicted a statistically significant $(\mathrm{p}<.05)$ portion of the variance (range, 1.48-3.96) in student broad reading (Table 5).

Table 6 represents the incremental validity evidence associated with adding WRCM to explain variation in broad reading, controlling for all CBM-comprehension assessments. 
This was done to examine the individual contribution of WRCM above that of CBMcomprehension scores to explain variation in broad reading scores. Controlling for all three measures of reading comprehension scores, WRCM explained a significant portion of the variation (range, 28.78-37.65) in broad reading scores within each grade (Table 6).

\section{Discussion}

This study, in part, tested the assumption that proficient reading rates indicate proficient comprehension, which is a published and often cited rationale for the use of CBM-R (Fuchs et al., 2001; Kuhn, et al., 2010). The implication is that students who perform at or above grade level standards on CBM-R are likely to achieve grade level standards on measures of reading comprehension. The results of this study suggest that there is a modest relationship in student performance on CBM-R and CBM-comprehension, but the classification consistency regarding proficiency and risk on the two measures was not substantial. There was a modest to large level of inconsistent classifications when CBM-R was used to evaluate comprehension proficiency.

In many cases, students who performed at or above proficiency on CBM-R did not meet proficiency standards on CBM-comprehension. Thus, using CBM-R alone does not fully indicate comprehension proficiency or deficits. Supplementing CBM-R with a comprehension assessment, such as CBM-comprehension, may provide a more accurate description of student reading profiles. The following sections provide further discussion of these and related conclusions along with potential implications for universal screening.

\section{Criterion Validity Evidence}

As the broadest measure of reading achievement, aReading was used as the primary criterion measure. Criterion validity coefficients between aReading and CBM-R were .77, .75, .72, and .65 in grades $2^{\text {nd }}$ to $5^{\text {th }}$ respectively (Table 2 ). Those coefficients are consistent with others reported in the literature over the span of 30 years that supports the strong relationship between rate and broad reading (Wayman et al., 2007). This was especially true in earlier grades.

In comparison, CBM-comprehension scores were consistently in the higher-modest range in relation to each other, suggesting that these brief supplemental tasks share systematic variance. In other words, the tasks require both reading comprehension and recall of the stored information following the CBM-R task. In addition, their criterion-related validity evidence to aReading was mostly in the moderate range. Although the assessments appear to measure oral reading comprehension, these findings support that the CBM-comprehension measures should be used to replace CBM-R or aReading. Instead, the information provided by the CBM-comprehension tasks may be used in combination with CBM-R to establish a more robust prediction of broad reading ability. Thus, an analysis of the diagnostic consistency between reading rate and comprehension was conducted.

\section{Diagnostic Consistency Evidence}

Adequate consistency would suggest that WRCM is an appropriate sole measure of comprehension. Poor consistency would suggest that the CBM-comprehension assessments 
may be a useful supplement to CBM-R. Results indicated the measures of comprehension and rate were inconsistent (Table 3; Figure 1). AUC estimates were better than chance (i.e., AUC > .5) but showed poor consistency (i.e., AUC < .7) between CBM-comprehension and CBM-R classifications (Table 3). In more specific terms, 12 to $24 \%$ of the time, readers with sufficient rate (i.e., not at risk based on WRCM) were at risk in comprehension (i.e., CBMcomprehension scores below benchmark). Likewise, readers with low reading rates were not at risk on the comprehension assessments 14 to $28 \%$ of the time (Table 3). These inconsistencies highlight potential misclassifications when CBM-R is used as a sole indicator of comprehension deficits.

In summary, the data and corresponding classifications are not consistent enough to conclude that reading rate sufficiently accounts for comprehension, which may have implications for screening in schools (discussed later). Thus, additional analyses were conducted to investigate if CBM-comprehension scores could be used to supplement WRCM by explaining additional variation in broad reading.

\section{Incremental Validity Evidence}

Multiple regression was used to conduct the incremental validity analysis. The analysis was used to explore whether the inconsistencies between rate and comprehension measures were statistically meaningful when the criterion was a measure of broad reading ability. Thus, the analysis provided insight to whether CBM-comprehension scores could provide meaningful information to supplement CBM-R. The results from the incremental validity analyses were similar to previous analyses (e.g., Christ et al., 2013; Fuchs et al., 1988; Marcotte \& Hintze, 2009). Overall, the combined scores for accuracy, rate, and comprehension explained a statistically significant and robust proportion of variance in broad reading performance (51$66 \%$; Table 4). The three CBM-comprehension scores collectively contributed only about $3 \%$ (range, 2-6\%) of additional variation in broad reading scores after controlling for WRCM and accuracy. Comprehension scores had higher explanatory power in later grades (Table 4), which could suggest that rate may becomes less import to broad reading after a certain threshold of ability is met. Regardless, these findings are consistent with past research (Jenkins \& Jewell, 1993).

CBM-comprehension scores explained unique variation in broad reading, which provides further evidence to support the interpretation and use of the CBM-comprehension assessments as indicators of broad reading ability. At minimum, these findings suggest that CBM-comprehension may provide additional evidence to support inferences guided by CBM-R about both broad reading ability and comprehension.

The data previously discussed suggest that (a) CBM-R is supported as a screener for broad reading achievement due to its criterion-related validity evidence, but CBM-comprehension scores in isolation do not possess sufficient criterion-related validity evidence; (b) there is poor consistency between CBM-R and CBM-comprehension score classifications; and (c) the variation in CBM-comprehension scores unique from (i.e., inconsistent with) WRCM explain significant variation in broad reading scores, even after controlling for WRCM and accuracy. Together, (d) these findings provide preliminary evidence supporting the interpretation and use of CBM-comprehension scores to supplement WRCM as screening 
indices indicative of broad reading achievement. The next section more explicitly relates these findings in terms of universal screening in schools for reading risk.

How Distinct is CBM-comprehension: Implications for Screening-The usefulness of CBM-R as a screening assessment indicative of broad reading ability is supported by past research (e.g., Reschly et al., 2009) and findings from the current study; however, findings from this study also suggests that CBM-R used as the sole measure of reading achievement is prone to classification errors. The classification inconsistencies between CBM-R and CBM-comprehension scores do not discredit the utility of CBM-R as a correlate of broad reading achievement. Instead, the inconsistencies suggest that CBM- $R$ may be insufficient in identifying some problems in reading comprehension. Thus, rate may not always provide a holistic picture of reading proficiency and risk (e.g., Tunmer \& Chapman, 2012).

FN classifications have the highest stakes, even though students who read at proficient rates with low comprehension are rare (Meisinger et al., 2009). Students in this classification group require intervention in reading comprehension. However, based on WRCM, these students will not be identified for the services that they need because their reading rate is in the proficient range. As a result, these students go undetected unless identified by teachers, which they often are not (Hamilton \& Shinn, 2003; Meisinger et al., 2009). An example is provided in Figure 2, which visually represents this for students in third grade on CompD. In this case, 417 students were able to read at a rate greater than 90 WRCM; however, none of them were able to recall at least seven details from the passage in two minutes. If CBM-R was only used for screening, these students were expected to have proficiency in both reading rate and comprehension, which is not the case.

The FP classification is less worrisome. Students in this classification are identified with insufficient reading rate and low comprehension through WRCM-alone when they actually comprehend at a proficient level. This is illustrated in the upper-left quadrant of Figure 2. These students will likely get what they need (i.e., reading rate interventions) with some potential boost to their already proficient comprehension skills (Shapiro, 2012). This means that FP classifications may be acceptable, pending school resources.

In conclusion, the data suggest that CBM-R can primarily be used alone as a predictor of broad reading ability. When only using CBM-R, students with deficits in reading rate (i.e., FP, TP) are likely to receive services that will address their needs. However, the few students who read at proficient rates with low comprehension will not receive what they need because CBM-R benchmarks will not indicate a deficit in comprehension for students who read at proficient rates. Generally, whether CBM-comprehension is included in universal screening efforts may depend on a number of factors such as resources, time, grade level, and acceptability.

A comprehension assessment might be a useful supplement to screening based on resources, with two potential delivery methods: (a) delivered as a follow-up diagnostic assessment to CBM-R or intervention selection to explore suspected concern that a student may have low comprehension despite sufficient reading rate, or (b) delivered as a part of universal 
screening to all students with proficient reading rates based on WRCM. Delivering the assessments as part of universal screening would be a resource intensive and low-yield strategy for schools, given the findings from this study and Meisinger et al. (2009).

The CBM-comprehension assessments require additional time to administer following CBM-R, which is already an individually administered assessment. Placing limitations on the assessments used and grades that are assessed could function as potential solutions if the additional 2-5 minutes per student is a problem. Of additional note is grade level and the goals of instruction. In earlier grades, the primary emphasis is on learning to read quickly and accurately; only in later grades does the focus shift to using reading to learn (Chall, 1993). As such, one approach could be to only screen for comprehension in the later grades. In addition, the data from the incremental validity analyses (Table 4) suggest that measures have different explanatory power based on grade level. In grade 2, CompQ and CompS are significant predictors of aReading; only CompD was significant in grade 3; and in grades 4 and 5 all CBM-comprehension measures were significant. These results likely require further exploration, but current findings suggest that the utility of certain comprehension measures changes by grade. Screening plans could be developed after determining important predictors, instructional goals, and grade levels of interest.

Research on CBM-R has primarily devoted attention to investigating the psychometric properties of the measures, in part, due to its lack of face validity. Teachers question that a one-minute sample of a student's WRCM is strongly associated with their overall reading abilities (Wayman, 2007). However, teachers believe in the utility of comprehension assessments (Ford et al., 2013). If teachers' acceptance of CBM-R is a work in progress, also including one or more of the CBM-comprehension measures could improve support for reading screening since they are administered following the final CBM-R passage.

In summary, schools' individual needs and resources should guide decision-making in this area. Regardless, adopting a method to identify these students is important. The NRP (2000) clearly states that the purpose of reading comprehension. Without sufficient comprehension, meaningful reading can not occur (Gough \& Tunmer, 1986).

Limitations and Future Directions-The data collection procedures introduce potential error. The data were accessed through an online assessment system where schools stored screening data. The schools were not necessarily trained to administer the assessments in standardized ways, though each assessment is accompanied by training materials. In short, procedural fidelity information such as the administration and scoring of the assessments remains unknown and a potential confound.

In terms of administration, CompD is especially difficult. Students may retell in nonsequential order, invent details, and incorporate inferences as they retell. It is likely that the ability of the administrator to accurately score oral retellings will depend on various factors (e.g., familiarity with the test and/or the speed at which the student recalls information) that resulted in unreliability of the estimates. Variability related to score reliability is also possible since each CBM-comprehension score is based on the student's ability to recall and answer questions regarding the third of three CBM-R probes. As a 
result, these scores may not be accurate estimates of a student's true score on CBMcomprehension assessments. Instead, scores may be limited to interpretation based on their comprehension of the single passage. Furthermore, passages were not counterbalanced, so each student received the passages in the same order. These concerns collectively relate to error. They are controlled for by sample size and adjustments for compounded type I error. Thus, the statistical conclusions that support interpretation and use of these data for reading theory, assessment, and screening are valid. However, studies with higher levels of experimental control are needed to support or contest the findings reported in the current study.

Future studies should investigate reliability estimates, such as test-retest and interrater reliability, for both the CompQ and CompD measures. Future studies should also investigate when and how comprehension assessments can be used to support students with comprehension-specific deficits in reading. Furthermore, additional research connecting these assessment procedures to middle and high school assessment to intervention practices is also needed to examine if findings are similar for students in later grades.

Developer benchmarks were used for WRCM classifications for the diagnostic consistency analysis. If the benchmarks used were lower or higher, the results would be different. However, these scores are calculated based on a national sample of students and approximate scores from other research (e.g., Tindal, Hasbrouk, \& Jones, 2005). Future research could explore similar analyses using CBM-R and CBM-comprehension assessments and benchmarks from different providers (e.g., Aimsweb, easyCBM).

In addition, the population that this study generalizes to is not entirely clear. Proficient readers (as determined by WRCM benchmarks) composed about $60 \%$ of the sample in grade 2 , about $50 \%$ of the sample in grades 3 and 4 , and about $40 \%$ of the sample in grade 5 (Table 1). Proficient readers (as determined by aReading benchmarks) within grades ranged from 31 to $45 \%$ of the sample, with the lowest in fifth grade. Although low, these scores were fairly similar to the NAEP (2015) findings. However, the student demographics in terms of race/ethnicity, disability status, and English language proficiency were not reported for the entire sample because of voluntary reporting. Future studies could investigate if these effects are different by race, disability status, or English Language proficiency.

In conclusion, the findings of the current study, which used extant data collected across a variety of schools and states for screening purposes, replicated results observed in studies with more experimental control of sampling mechanisms and data collection procedures. This strengthens the external validity evidence and extends current understanding regarding the interpretations and uses of CBM-R and CBM-comprehension in the classroom to inform instructional practices. The two measures are related, yet they also provide unique information. CBM-R is a sufficient screener of student reading abilities that will likely link to proper reading interventions. However, when students are proficient readers in terms of rate but have low comprehension, additional assessments in reading comprehension, such as the CBM-comprehension, could be used to reduce the rate of misclassifications or confirm reading skills. Thus, students have a better chance of receiving the right intervention services to support their success in reading and their access to the curriculum. 


\section{Acknowledgments}

Dr. Theodore Christ has received royalties from Fastbridge Learning.

Funding

Preparation of this manuscript was supported in part by grants from the Office of Special Education Programs, U.S. Department of Education (H327S150004; R305A120086) and the National Institute of Mental Health, U.S. Department of Health and Human Services (5T32MH010026).

\section{References}

Ardoin SP, Eckert TL, Christ TJ, White MJ, Morena LS, January S-AA, Hine JF. 2013; Examining variance in reading comprehension among developing readers: Words in context (curriculum-based measurement in reading) versus words out of context (word lists). School Psychology Review. 42(3):243.

Ball CR, Christ TJ. 2012; Supporting valid decision making: Uses and misuses of assessment data within the context of RTI. Psychology in the Schools. 49(3):231-244. DOI: 10.1002/pits.21592

Carlson SE, Seipel B, McMaster K. 2014; Development of a new reading comprehension assessment: Identifying comprehension differences among readers. Learning and Individual Differences. 32:40 53. DOI: 10.1016/j.lindif.2014.03.003

Chall, JS. Stages of reading development. New York: McGraw-Hill; 1983.

Christ TJ, Aranas YA. 2014; Best practices in problem analysis. Best Practices in School Psychology V. 2:159-176.

Christ TJ, Keller-Margulis MA. 2014; CBA: Curriculum-based Assessment. Academic Assessment and Intervention. 117

Christ TJ, White MJ, Ardoin SP, Eckert TL. 2013; Curriculum Based Measurement of Reading: Consistency and validity across best, fastest, and question reading conditions. School Psychology Review. 42(4):415.

Davis MH, Guthrie JT. 2015; Measuring reading comprehension of content area texts using an assessment of knowledge organization. The Journal of Educational Research. 108(2):148-164. DOI: 10.1080/00220671.2013.863749

Deno SL. 1985; Curriculum-based measurement: The emerging alternative. Exceptional Children. 52(3):219-232. [PubMed: 2934262]

Ehri LC. 2005; Learning to read words: Theory, findings, and issues. Scientific Studies of Reading. 9(2):167-188.

Ford JW, Missall KN, Hosp JL, Kuhle JL. 2016; Comparing two cbm maze selection tools: Considering scoring and interpretive metrics for universal screening. Journal of Applied School Psychology. 32(4):329-353.

Fuchs D, Fuchs LS. 2006; Introduction to response to intervention: What, why, and how valid is it? Reading Research Quarterly. 41(1):93-99. DOI: 10.1598/RRQ.41.1.4

Fuchs D, Fuchs LS, Compton DL. 2004; Identifying Reading Disabilities by Responsiveness-toInstruction: Specifying Measures and Criteria. Learning Disability Quarterly. 27(4):216.doi: 10.2307/1593674

Fuchs LS, Fuchs D, Maxwell L. 1988; The validity of informal reading comprehension measures. Remedial and Special Education. 9(2):20-28.

Fuchs LS, Fuchs D, Hosp MK, Jenkins JR. 2001; Oral Reading Fluency as an Indicator of Reading Competence: A Theoretical, Empirical, and Historical Analysis. Scientific Studies of Reading. 5(3):239-256. DOI: 10.1207/S1532799XSSR0503_3

Good, RH, Kaminski, RA. Dynamic Indicators of Basic Early Literacy Skills. 6. Eugene, OR: Institute for the Development of Educational Achievement; 2002.

Gough PB, Tunmer WE. 1986; Decoding, reading, and reading disability. Remedial and Special Education. 7(1):6-10. 
Graesser, A, Hu, X. Conclusion: Moving forward on reading assessment. In: Sabatini, J, Albro, E, O'Reilly, T, editors. Measuring Up. Plymouth, UK: Rowman \& Littlefield Education; 2012. 153158.

Graney SB, Martínez RS, Missall KN, Aricak OT. 2010; Universal Screening of Reading in Late Elementary School R-CBM Versus CBM Maze. Remedial and Special Education. 31(5):368-377. DOI: $10.1177 / 0741932509338371$

Hintze JM, Silberglitt B. 2005; A longitudinal examination of the diagnostic accuracy and predictive validity of R-CBM and high-stakes testing. School Psychology Review. 34(3):372.

Jenkins JR, Jewell M. 1993; Examining the validity of two measures for formative teaching: reading aloud and maze. Exceptional Children. 59(5):421-432.

Kane M. 2013; The argument-based approach to validation. School Psychology Review. 42(4):448.

Kendeou P, Papadopoulos TC, Spanoudis G. 2012; Processing demands of reading comprehension tests in young readers. Learning and Instruction. 22(5):354-367. DOI: 10.1016/j.learninstruc. 2012.02.001

Kilgus SP, Methe SA, Maggin DM, Tomasula JL. 2014; Curriculum-based measurement of oral reading (R-CBM): A diagnostic test accuracy meta-analysis of evidence supporting use in universal screening. Journal of School Psychology. 52(4):377-405. DOI: 10.1016/j.jsp. 2014.06.002 [PubMed: 25107410]

Kranzler JH, Miller MD, Jordan L. 1999; An examination of racial/ethnic and gender bias on curriculum-based measurement of reading. School Psychology Quarterly. 14(3):327.doi: 10.1037/ h0089012

Kuhn MR, Schwanenflugel PJ, Meisinger EB, Levy BA, Rasinski TV. 2010; Aligning theory and assessment of reading fluency: Automaticity, prosody, and definitions of fluency. Reading Research Quarterly. 45(2):230-251.

Marcotte AM, Hintze JM. 2009; Incremental and predictive utility of formative assessment methods of reading comprehension. Journal of School Psychology. 47(5):315-335. DOI: 10.1016/j.jsp. 2009.04.003 [PubMed: 19712779]

McNamara, DS, Magliano, J. Toward a comprehensive model of comprehension. In: Ross, B, editor. Psychology of Learning and Motivation. 2009. 297-384.

Meisinger EB, Bradley BA, Schwanenflugel PJ, Kuhn MR, Morris RD. 2009; Myth and reality of the word caller: The relation between teacher nominations and prevalence among elementary school children. School Psychology Quarterly. 24(3):147-159. [PubMed: 20161567]

Morgan PL, Sideridis G, Hua Y. 2012; Initial and Over-Time Effects of Fluency Interventions for Students with or at Risk for Disabilities. Journal of Special Education. 46(2):94-116.

National Center for Response to Intervention. Screening Tools Chart Rating System. U.S. Office of Special Education Programs; 2015.

National Governors Association Center for Best Practices, Council of Chief State School Officers. National Governors Association Center for Best Practices, Council of Chief State School Officers. Washington D.C.: 2010. Common core state standards: English language arts.

National Reading Panel. Report of the National Reading Panel Subgroups: Teaching children to read. National Institute of Child Health and Human Development; 2000.

Perfetti, C, Adlof, SM. Reading comprehension: A conceptual framework from word meaning to text meaning. In: Sabatini, J, Albro, E, O'Reilly, T, editors. Measuring Up. Plymouth, UK: Rowman \& Littlefield Education; 2012. 153-158.

Reschly AL, Busch TW, Betts J, Deno SL, Long JD. 2009; Curriculum-Based Measurement Oral Reading as an indicator of reading achievement: A meta-analysis of the correlational evidence. Journal of School Psychology. 47(6):427-469. DOI: 10.1016/j.jsp.2009.07.001 [PubMed: 19808123]

Reynolds AJ, Temple JA, White BAB, Ou S-R, Robertson DL. 2011; Age 26 Cost-Benefit Analysis of the Child-Parent Center Early Education Program: Cost-Benefit Analysis. Child Development. 82(1):379-404. DOI: 10.1111/j.1467-8624.2010.01563.x [PubMed: 21291448]

Schochet, PZ. Technical Methods Report: Guidelines for Multiple Testing in Impact Evaluations. NCEE; 2008. (No. NCEE 20084018) 
Shapiro, ES. Academic Skills Problems : Direct Assessment and Intervention. New York, US: Guilford Press; 2012.

Stanovich KE. 1986Matthew effects in reading: Some consequences of individual differences in the acquisition of literacy. Reading Research Quarterly. :360-407.

Strickland WD, Boon RT, Spencer VG. 2013; The Effects of Repeated Reading on the Fluency and Comprehension Skills of Elementary-Age Students with Learning Disabilities (LD), 2001-2011: A Review of Research and Practice. Learning Disabilities. A Contemporary Journal. 11(1):1-33.

Swets JA, Dawes RM, Monahan J. 2000; Psychological science can improve diagnostic decisions. Psychological Science in the Public Interest. 1:1-26. [PubMed: 26151979]

Theodore, J, Christ, et al. Formative Assessment System for Teachers: Technical Manual Version 2.0. Minneapolis, MN: Author and Fast Bridge Learning; 2015. (fastbridge.org)

Tindal G. 2013; Curriculum-Based Measurement: A Brief History of Nearly Everything from the 1970s to the Present. ISRN Education. 2013:1-29. DOI: 10.1155/2013/958530

Tunmer WE, Chapman JW. 2012; The simple view of reading redux vocabulary knowledge and the independent components hypothesis. Journal of Learning Disabilities. 45(5):453-466. [PubMed: 22293683]

Tunmer WE, Chapman JW. 2012; The simple view of reading redux vocabulary knowledge and the independent components hypothesis. Journal of Learning Disabilities. 45(5):453-466. [PubMed: 22293683]

VanDerHeyden AM, Burns MK. 2017; Four dyslexia screening myths that cause more harm than good in preventing reading failure and what you can do instead. Communique. 45(7)

Wayman MM, Wallace T, Wiley HI, Tichá R, Espin CA. 2007; Literature synthesis on curriculumbased measurement in reading. The Journal of Special Education. 41(2):85-120.

Wiley HI, Deno SL. 2005; Oral reading and maze measures as predictors of success for English learners on a state standards assessment. Remedial \& Special Education. 26(4):207-214.

Yang, J. A meta-analysis of the effects of interventions to increase reading fluency among elementary school students. 2007. Retrieved from http://search.proquest.com.ezp2.lib.umn.edu/llba/docview/ 85656472/A6D9B471C5CC48FAPQ/2

\section{Biographies}

Calvary R. Diggs

Calvary has a MA degree in Educational Psychology from the University of Minnesota. His current research interests focus on the adoption, use, and refinement of assessment to intervention systems in school settings.

Theodore J. Christ

Ted is a professor of educational and school psychology at the University of Minnesota. His current research interests focus on innovation in cloud-based assessment and interventions. 

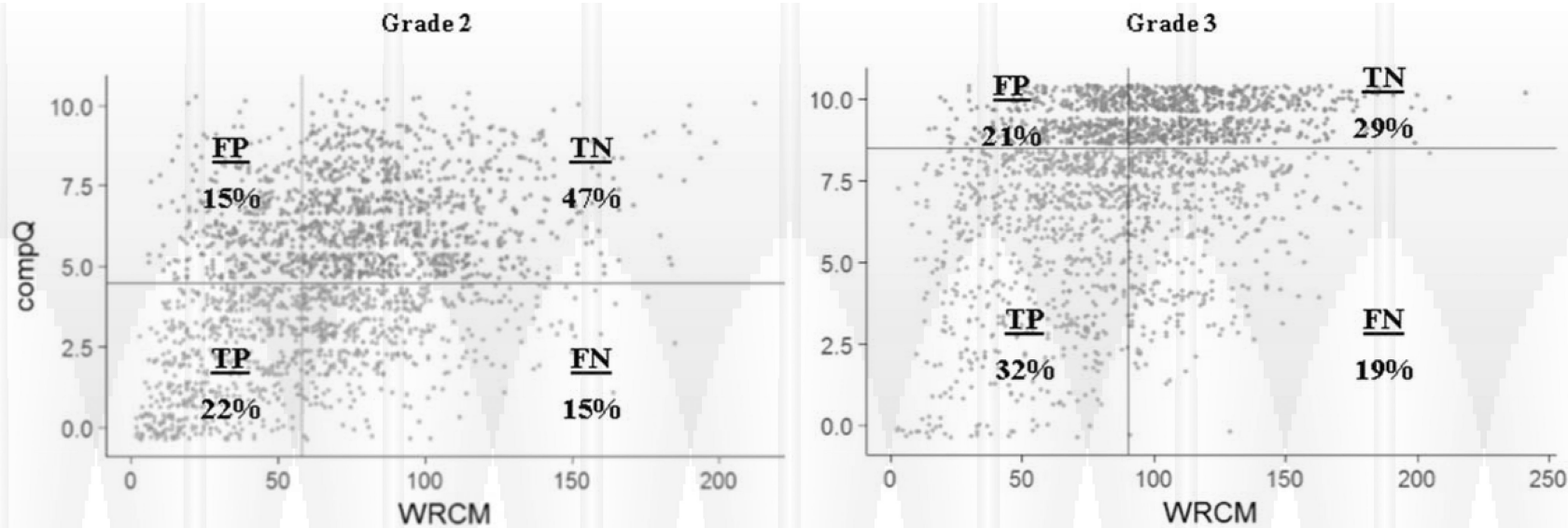

Grade 4

Grade 5
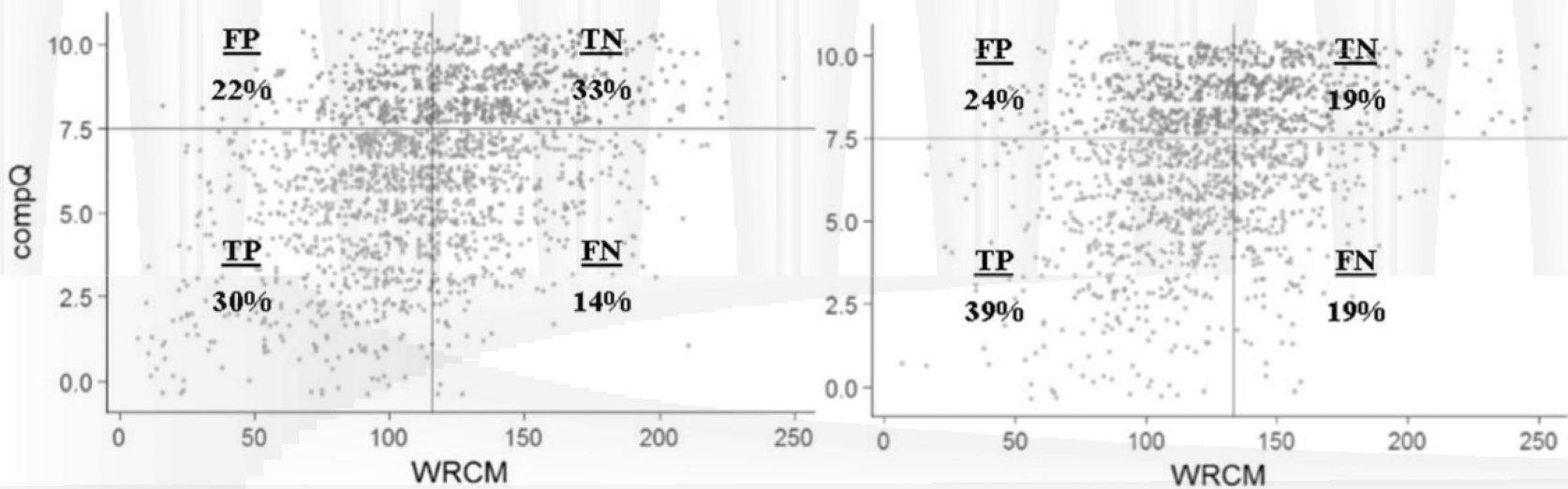

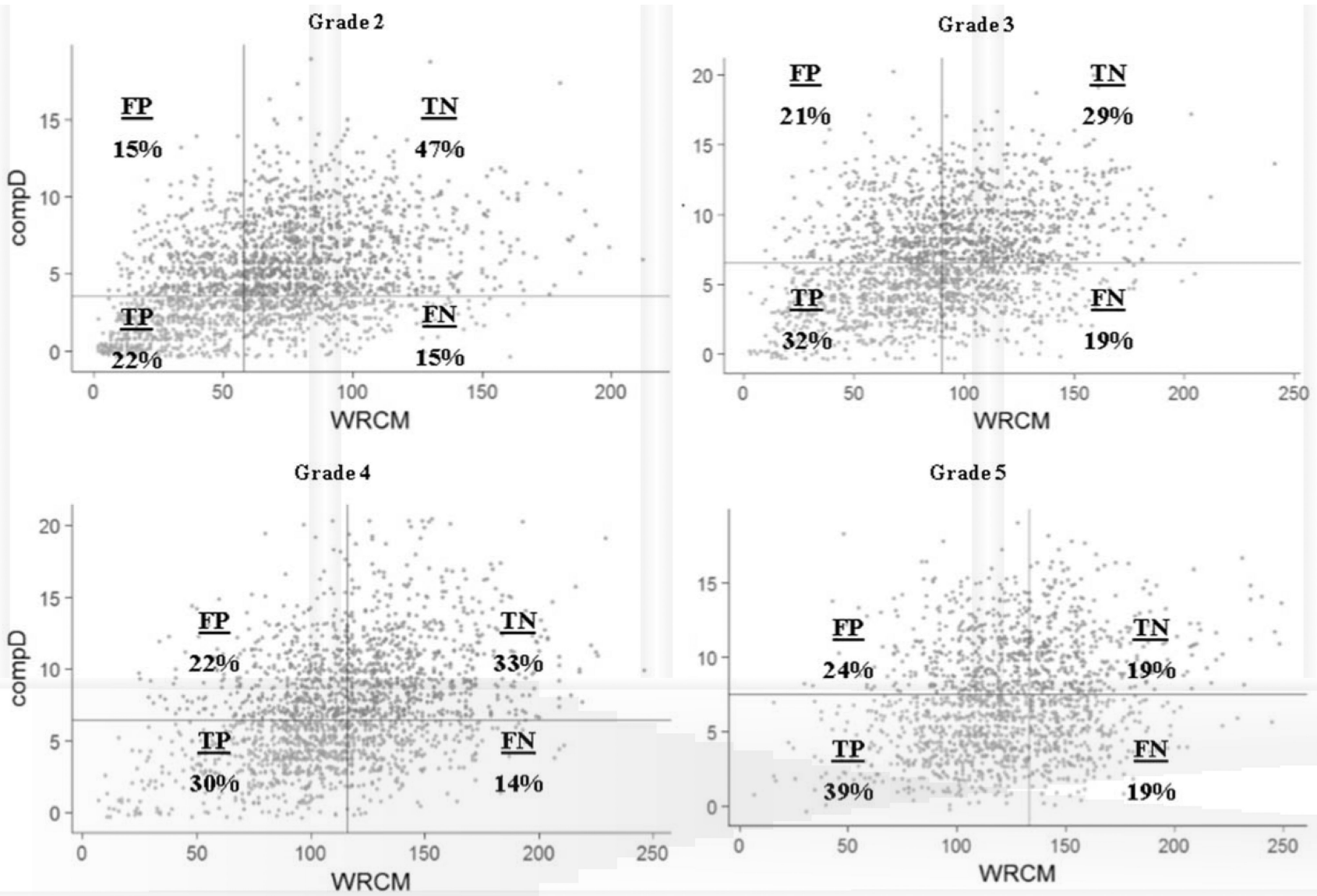

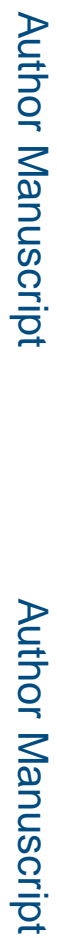

Contemp Sch Psychol. Author manuscript; available in PMC 2020 June 01. 

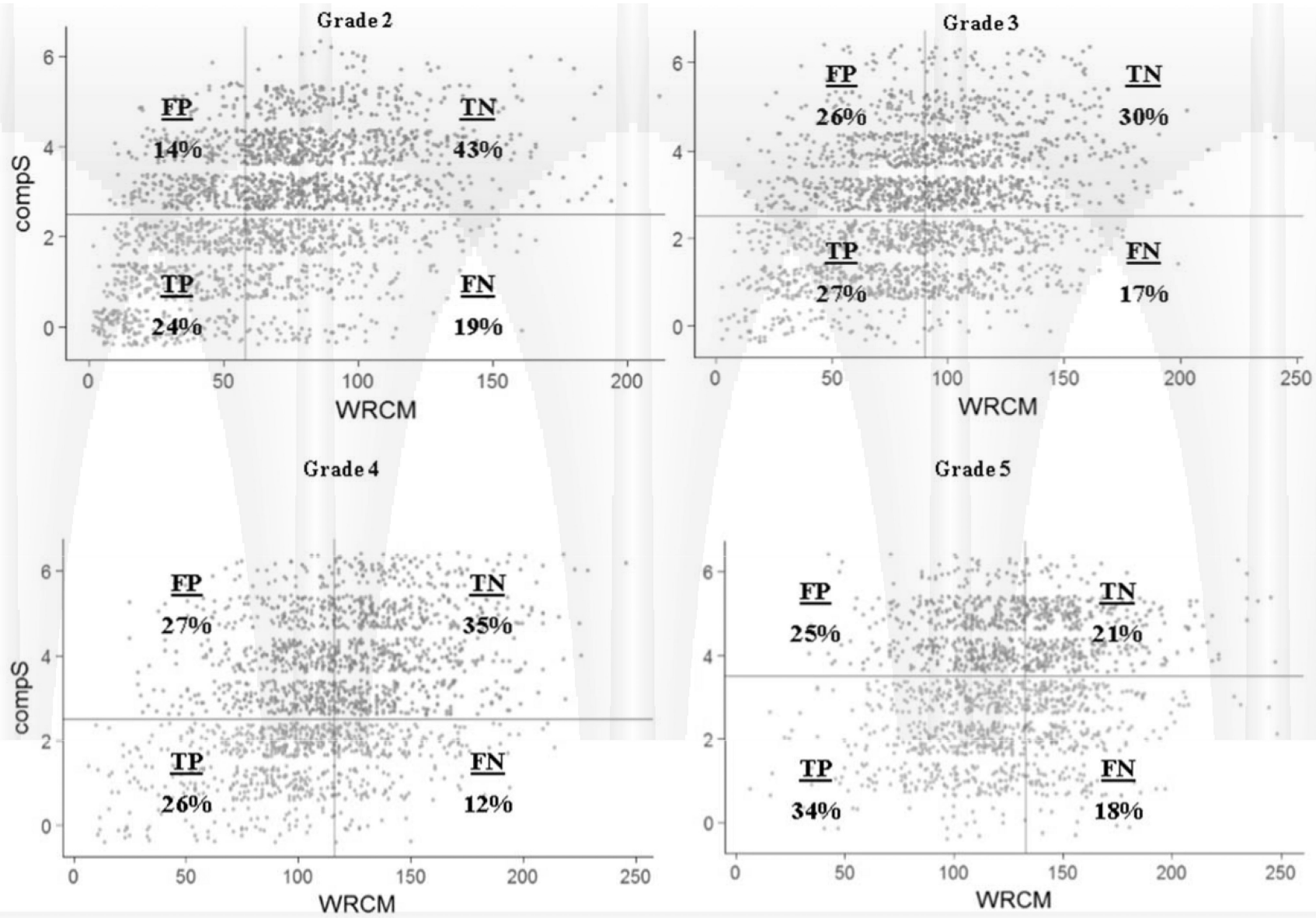

Figure 1.

Descriptive representation of base rates from the diagnostic consistency analyses for words read correct a minute compared to comprehension questions (CompQ), comprehension detailed (CompD), and comprehension synthesis (CompS). Each quadrant represents the true positive (TP), true negative (TN), false positive (FP), and false negative (FN) classifications between the CBM-comprehension measures and CBM-reading. TP is indicative of low rate and low comprehension; $\mathrm{TN}$ is indicative of sufficient rate and comprehension; FP indicates low rate and high comprehension; FN represents high rate and low comprehension. The percentages are represented as proportions, calculated by dividing the total number of students receiving a particular classification divided by the total number of students in that grade. 


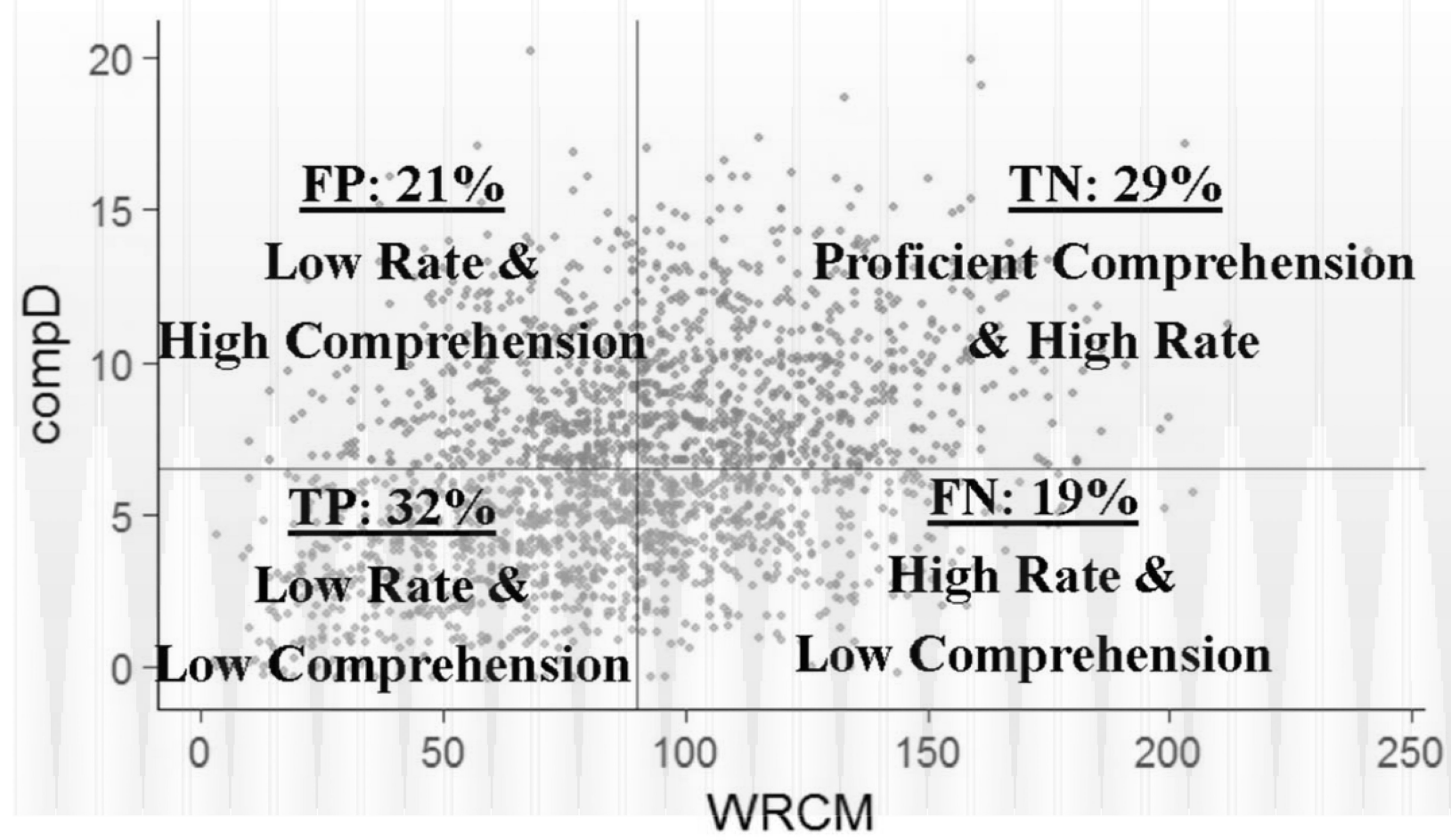

Figure 2.

Grade 3 student diagnostic consistency results based on words read correct a minute (WRCM) compared to comprehension detailed. In addition to True Positive, True Negative, False Positive, False Negative classifications, each quadrant also provides what those classification means In terms of reading performance. The $\mathrm{Y}$ axis is the score on comprehension detailed. 

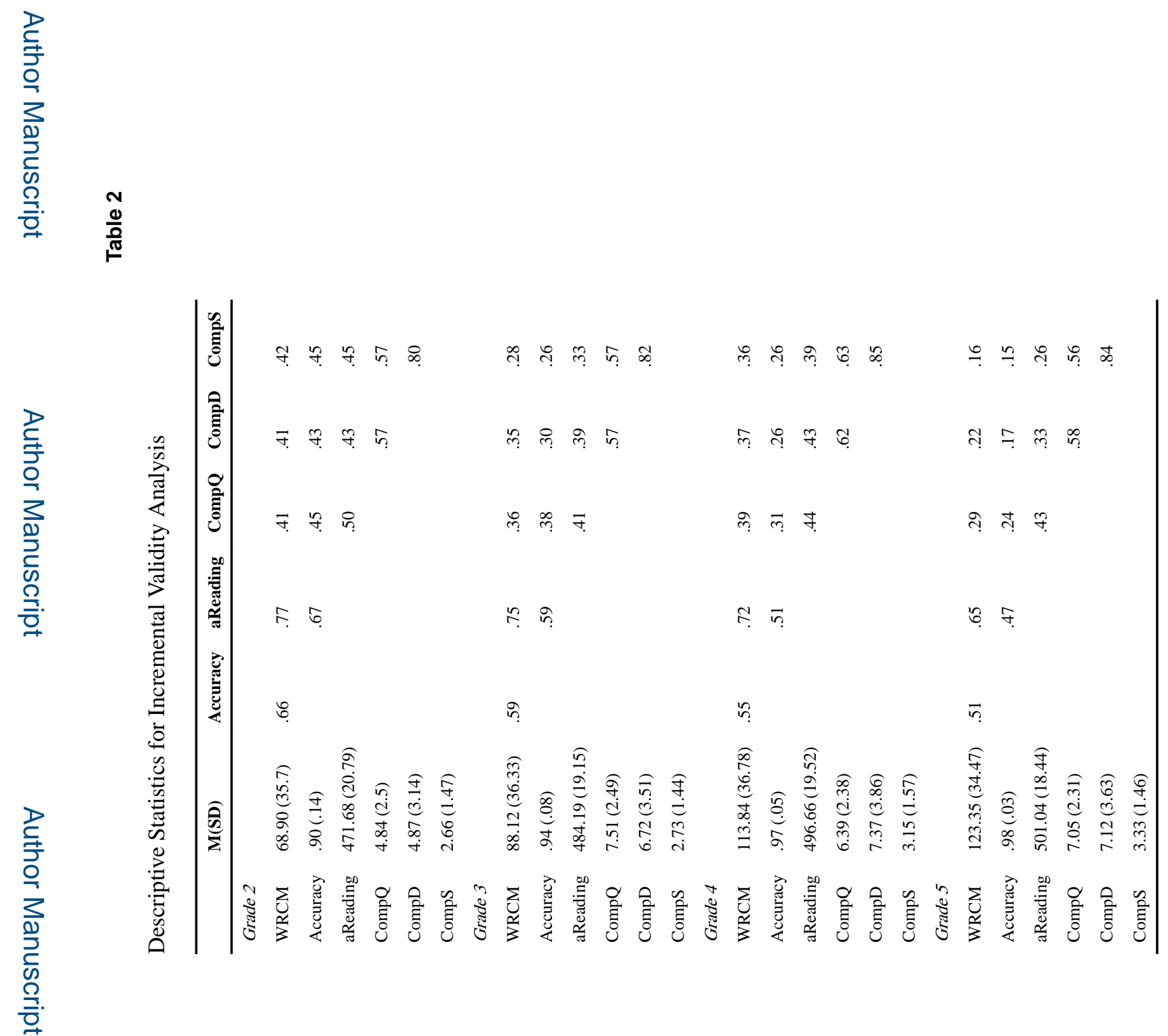

Contemp Sch Psychol. Author manuscript; available in PMC 2020 June 01. 


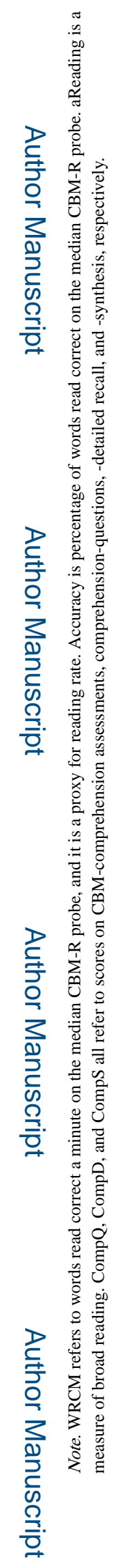




\section{를}

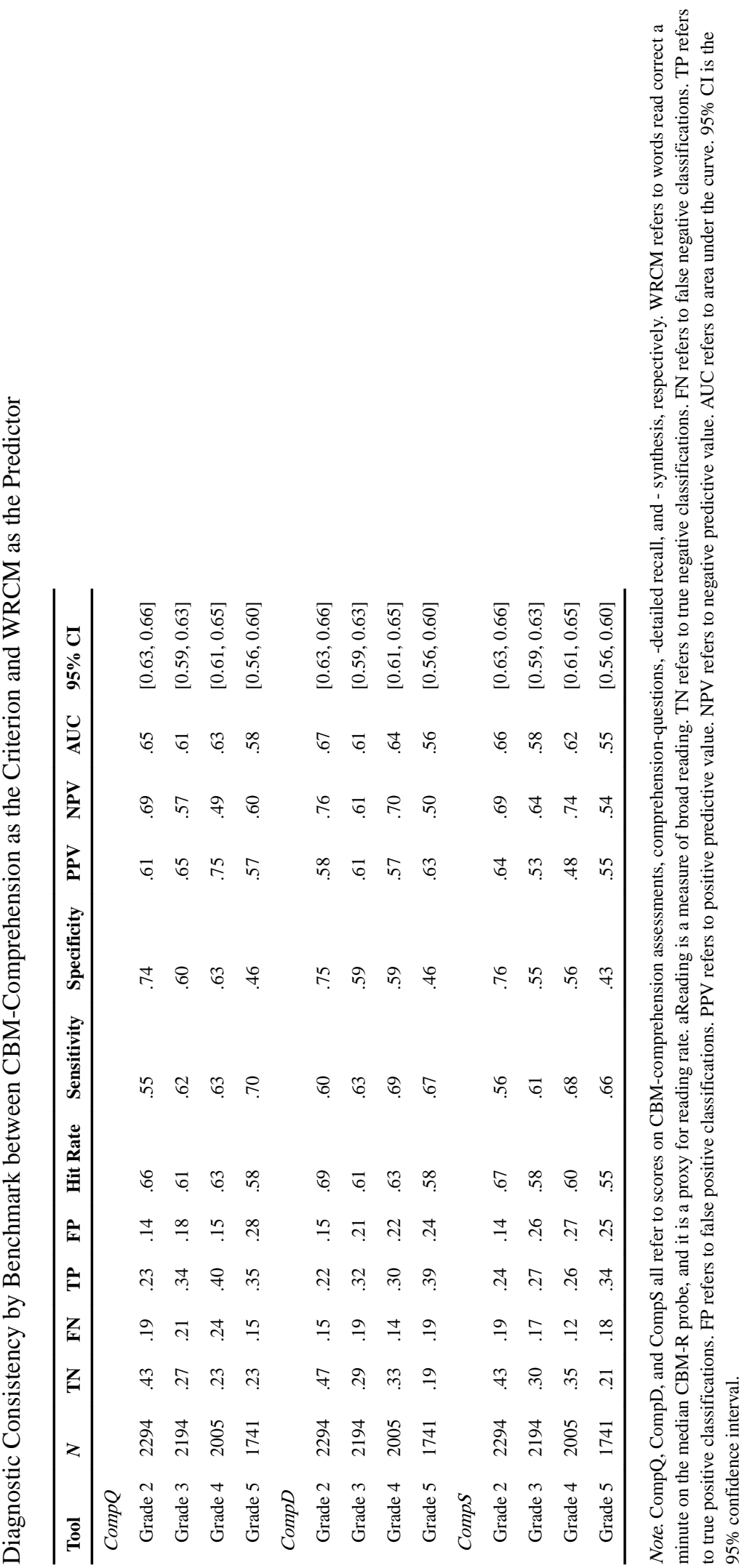

Contemp Sch Psychol. Author manuscript; available in PMC 2020 June 01. 


\section{을 \\ 길}

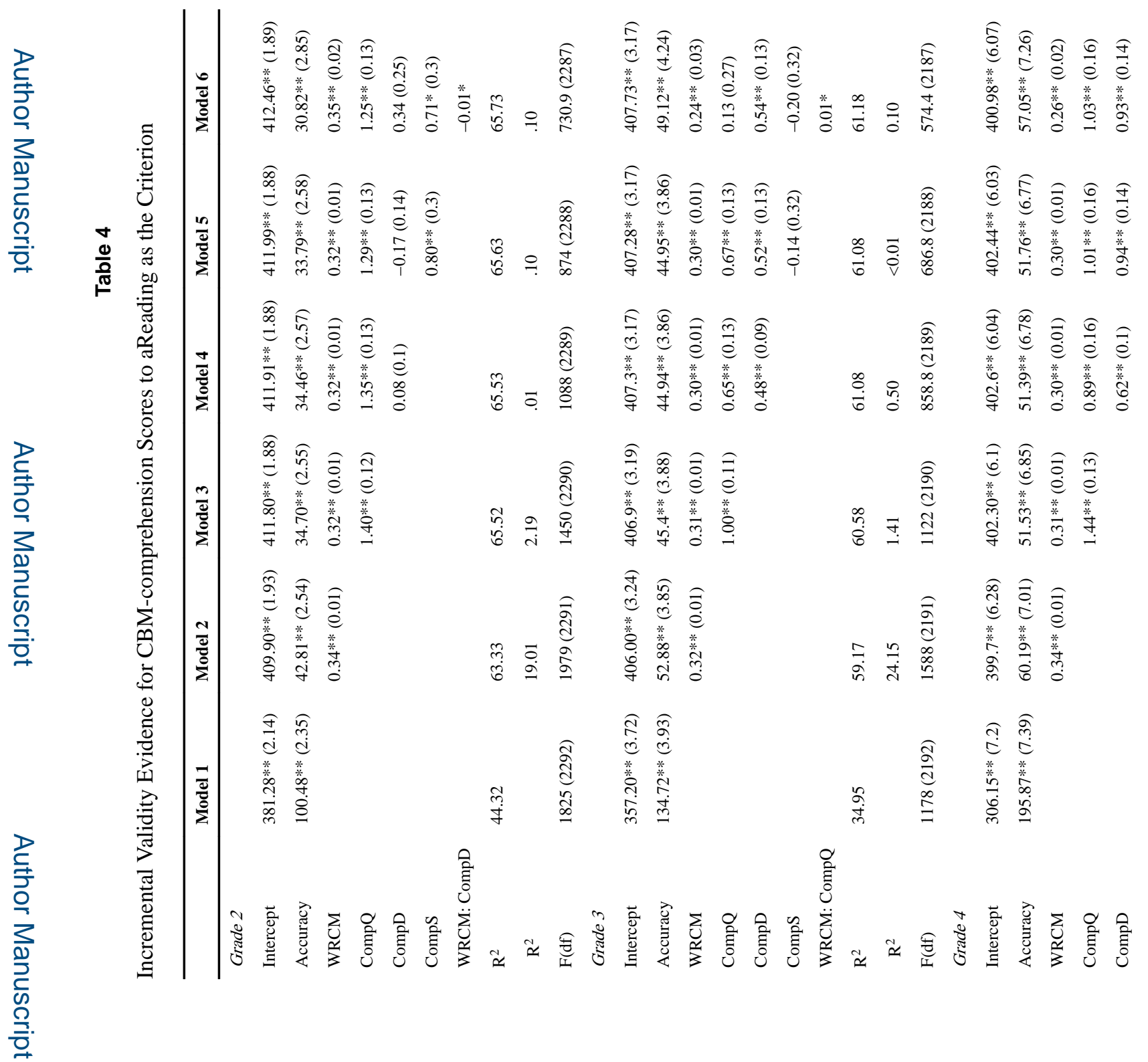

Contemp Sch Psychol. Author manuscript; available in PMC 2020 June 01. 


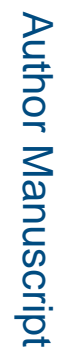

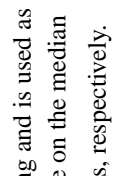

bo 0.

ఏ્气

उ

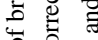

욜

哓

范

要

㤗

郭

s.

3

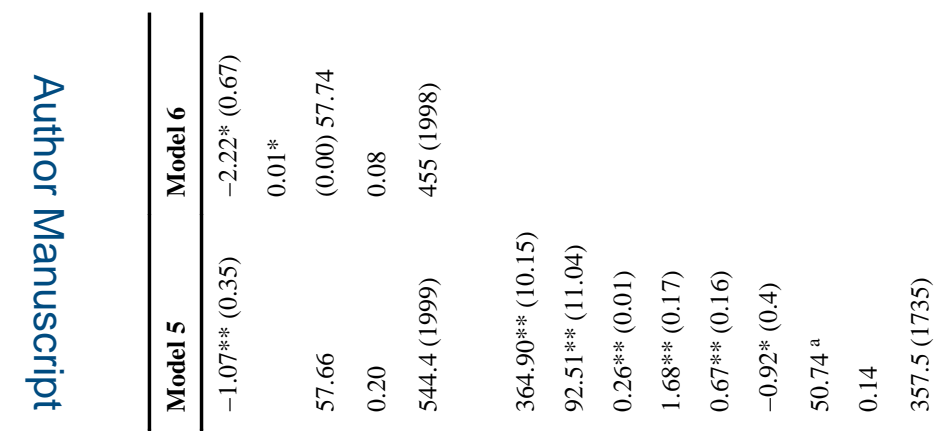
бㅇㅇㅇ 递 部

응.

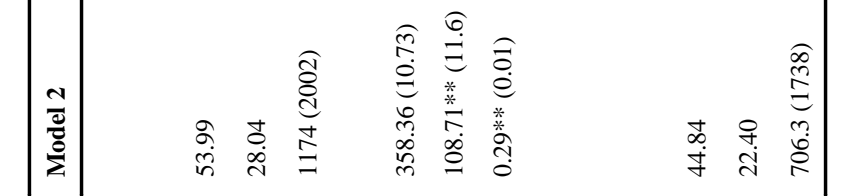

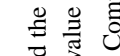

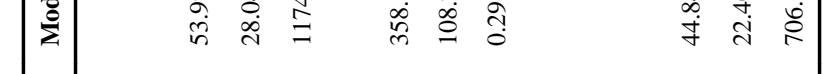

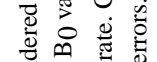

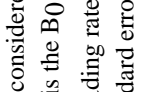

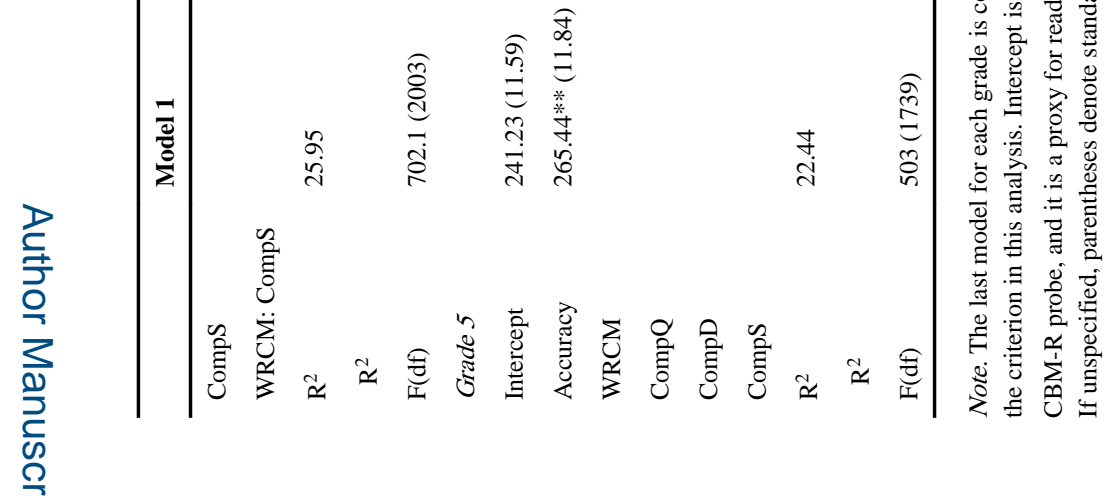

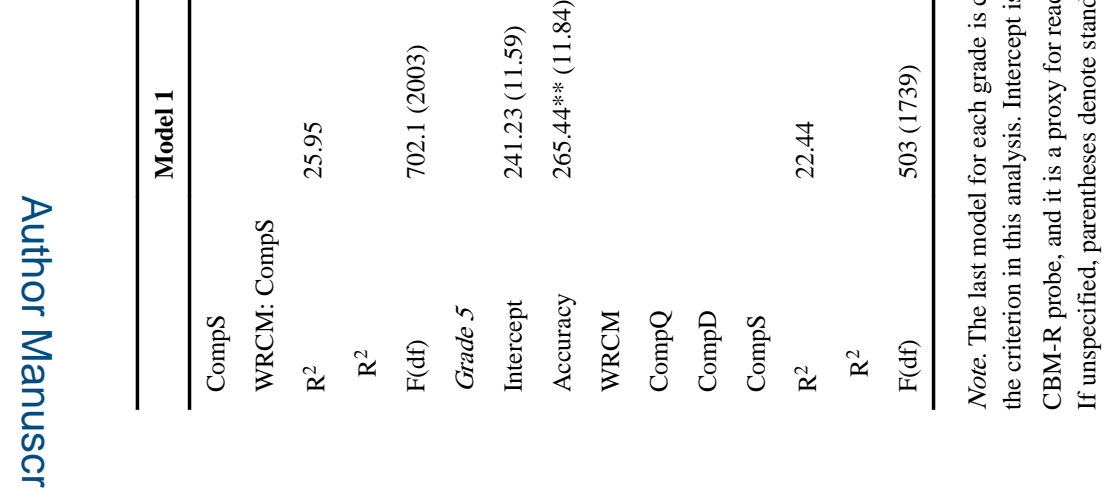

Contemp Sch Psychol. Author manuscript; available in PMC 2020 June 01. 
Table 5

Incremental Validity Evidence for individual CBM-comprehension Scores to aReading

\begin{tabular}{|c|c|c|c|c|}
\hline & $\begin{array}{l}\text { Model 1: } \\
\text { WRCM } \\
\text { Only }\end{array}$ & $\begin{array}{l}\text { Model 2: } \\
\text { + CompQ }\end{array}$ & $\begin{array}{l}\text { Model 3: } \\
\text { + CompD }\end{array}$ & $\begin{array}{l}\text { Model 4: } \\
\text { + CompS }\end{array}$ \\
\hline \multicolumn{5}{|l|}{ Grade 2} \\
\hline Intercept $\left(\mathrm{B}_{0}\right)$ & $440.9 * *(0.61)$ & $435.80 * *(0.66)$ & $438.80^{* *}(0.64)$ & $437.6 * *(0.66$ \\
\hline WRCM & $0.46^{* *}(0.01)$ & $0.39 * *(0.01)$ & $0.14 * *(0.01)$ & $0.41 * *(0.01)$ \\
\hline CompQ & & $1.81 * *(0.12)$ & & \\
\hline CompD & & & $0.88 * *(0.10)$ & \\
\hline CompS & & & & $2.25 * *(0.20)$ \\
\hline $\mathrm{R}^{2}$ & 58.78 & 62.74 & 60.26 & 60.87 \\
\hline$\Delta \mathrm{R}^{2}$ from Model 1 & & 3.96 & 1.48 & 2.09 \\
\hline $\mathrm{F}(\mathrm{df})$ & $3269(2292)$ & $1929(2291)$ & $1737(2291)$ & $1782(2291)$ \\
\hline \multicolumn{5}{|l|}{ Grade 3} \\
\hline Intercept $\left(\mathrm{B}_{0}\right)$ & $449.5 * *(0.71)$ & $442.70 * *(0.92)$ & $464.40^{* *}(0.76)$ & $446.5^{* *}(0.78)$ \\
\hline WRCM & $0.39 * *(0.01)$ & $0.36 * *(0.01)$ & $0.37 * *(0.01)$ & $0.37 * *(0.01)$ \\
\hline CompQ & & $1.29 * *(0.11)$ & & \\
\hline CompD & & & $.84^{* *}(0.08)$ & \\
\hline CompS & & & & $1.74 * *(0.19)$ \\
\hline $\mathrm{R}^{2}$ & 55.66 & 58.11 & 57.74 & 57.23 \\
\hline$\Delta \mathrm{R}^{2}$ from Model 1 & & 2.45 & 2.08 & 1.58 \\
\hline $\mathrm{F}(\mathrm{df})$ & 2751(2192) & $1520(2191)$ & 1496(2191) & $1466(2191)$ \\
\hline \multicolumn{5}{|l|}{ Grade 4} \\
\hline Intercept $\left(\mathrm{B}_{0}\right)$ & $452.97 * * 0.98$ & $448.50 * * 1.06$ & $450.20 * * 0.98$ & $450.45^{* *} 1.00$ \\
\hline WRCM & $0.38 * *(0.01)$ & $0.34 * *(0.01)$ & $0.35 * *(0.01)$ & $0.36 * *(0.01)$ \\
\hline CompQ & & $1.56 * *(0.13)$ & & \\
\hline CompD & & & $0.96 * *(0.08)$ & \\
\hline CompS & & & & $1.80 * *(0.20)$ \\
\hline $\mathrm{R}^{2}$ & 52.29 & 55.35 & 55.37 & 54.11 \\
\hline$\Delta \mathrm{R}^{2}$ from Model 1 & & 3.06 & 3.08 & 1.82 \\
\hline $\mathrm{F}(\mathrm{df})$ & $2195(2003)$ & 1241(2002) & $1242(2002)$ & 1180(2002) \\
\hline \multicolumn{5}{|l|}{ Grade 5} \\
\hline Intercept $\left(\mathrm{B}_{0}\right)$ & $457.3 * *(1.25)$ & $448.60 * *(1.36)$ & $454.10^{* *}(1.27)$ & $435.32 * *(1.35)$ \\
\hline WRCM & $0.35 * *(0.01)$ & $0.31 * *(0.01)$ & $0.32 * *(0.01)$ & $0.33 * *(0.01)$ \\
\hline CompQ & & $2.08 * *(0.14)$ & & \\
\hline CompD & & & $0.99 * *(0.09)$ & \\
\hline CompS & & & & $2.00 * *(0.23)$ \\
\hline $\mathrm{R}^{2}$ & 42.05 & 45.59 & 44.49 & 19.97 \\
\hline$\Delta \mathrm{R}^{2}$ from Model 1 & & 2.66 & 3.76 & 2.83 \\
\hline $\mathrm{F}(\mathrm{df})$ & $1262(1739)$ & $810.2(1738)$ & $728.3(1738)$ & $696.6(1738)$ \\
\hline
\end{tabular}

Contemp Sch Psychol. Author manuscript; available in PMC 2020 June 01. 
Note. aReading is a measure of broad reading and is used as the criterion in this analysis. Intercept is the $\mathrm{B}_{0}$ value for the model. WRCM refers to words read correct a minute on the median CBM-R probe, and it is a proxy for reading rate. CompQ, CompD, and CompS all refer to scores CBMcomprehension assessments, comprehension-questions, -detailed recall, and -synthesis, respectively. If unspecified, parentheses denote standard errors. 


\section{Table 6}

Incremental Validity Evidence for WRCM to aReading as the Criterion

\begin{tabular}{|c|c|c|}
\hline & $\begin{array}{l}\text { Model 1: } \\
\text { All CBM-comp }\end{array}$ & $\begin{array}{l}\text { Model 2: } \\
\text { + WRCM }\end{array}$ \\
\hline \multicolumn{3}{|l|}{ Grade 2} \\
\hline Intercept & $448.12(0.86)$ & $435.03(0.68)$ \\
\hline CompQ & $2.86(0.18)$ & $1.56(0.13)$ \\
\hline CompD & $0.51(0.20)$ & $-0.14(0.15)$ \\
\hline CompS & $2.71(0.43)$ & $1.19(0.31)$ \\
\hline WRCM & & $0.39(0.01)$ \\
\hline $\mathrm{R}^{2}$ & 29.02 & 63.06 \\
\hline$\Delta \mathrm{R}^{2}$ & & 34.04 \\
\hline $\mathrm{F}(\mathrm{df})$ & $312(2290)$ & $976.9(2289)$ \\
\hline \multicolumn{3}{|l|}{ Grade 3} \\
\hline Intercept & $459.47(1.16)$ & $442.72(0.92)$ \\
\hline CompQ & $2.25(0.18)$ & $0.94(0.14)$ \\
\hline CompD & $1.58(0.19)$ & $0.50(0.14)$ \\
\hline CompS & $-1.03(0.45)$ & $-0.14(0.33)$ \\
\hline WRCM & & $0.35(0.01)$ \\
\hline $\mathrm{R}^{2}$ & 21.02 & 58.67 \\
\hline$\Delta \mathrm{R}^{2}$ & & 37.65 \\
\hline $\mathrm{F}(\mathrm{df})$ & 194.2(2190) & 776.7(2189) \\
\hline \multicolumn{3}{|l|}{ Grade 4} \\
\hline Intercept & $472.27(1.1)$ & $447.86(1.05)$ \\
\hline CompQ & $2.41(0.21)$ & $1.11(0.16)$ \\
\hline CompD & $1.49(0.19)$ & $0.93(0.14)$ \\
\hline CompS & $-0.63(0.48)$ & $-1.03(0.36)$ \\
\hline WRCM & & $0.33(0.01)$ \\
\hline $\mathrm{R}^{2}$ & 23.92 & 56.42 \\
\hline$\Delta \mathrm{R}^{2}$ & & 32.5 \\
\hline $\mathrm{F}(\mathrm{df})$ & 209.7(2001) & $647.3(2000)$ \\
\hline \multicolumn{3}{|l|}{ Grade 5} \\
\hline Intercept & $477.64(1.31)$ & $449.21(1.39)$ \\
\hline CompQ & $2.97(.21)$ & $1.80(0.17)$ \\
\hline CompD & $1.22(0.21)$ & $0.64(0.17)$ \\
\hline CompS & $-1.88(0.51)$ & $-0.80(0.41)$ \\
\hline WRCM & & $0.30(0.01)$ \\
\hline $\mathrm{R}^{2}$ & 19.97 & 48.75 \\
\hline$\Delta \mathrm{R}^{2}$ & & 28.78 \\
\hline $\mathrm{F}(\mathrm{df})$ & $144.5(1737)$ & $412.9(1736)$ \\
\hline
\end{tabular}

Note. aReading is a measure of broad reading and is used as the criterion in this analysis. Intercept is the $\mathrm{B}_{0}$ value for the model. WRCM refers to words read correct a minute on the median CBM-R probe, and it is a proxy for reading rate. CompQ, CompD, and CompS all refer to scores CBM- 
comprehension assessments, comprehension-questions, -detailed recall, and -synthesis, respectively. If unspecified, parentheses denote standard errors. 